\title{
EXPERIMENTAL OBSERVATIONS ON THE EFFECT OF VARIOUS DIURETICS WHEN INJECTED DIRECTLY INTO ONE RENAL ARTERY OF THE DOG ${ }^{1}$

\author{
BY EDWARD A. BARTRAM
}

(From the Medical Clinic of Dr. Henry A. Christian at the Peter Bent Brigham Hospital, and the Laboratory of the Department of Medicine of the Harvard Medical School, Boston)

(Received for publication June 25, 1932)

In the study of the action of diuretics the first question to determine is whether the drug acts directly on the kidney, or indirectly through changes in the blood or in the circulation. Since the publication of the theories of urine secretion advanced by Bowman, Heidenhain and Ludwig, an extensive literature has sprung up in an effort to add light to this problem. Experimental results have, however, been conflicting.

Von Schroeder (1) in 1888 first examined the action of caffeine, theobromine and theophylline on the kidney of the rabbit, cat and dog. He felt that diuresis was due to a specific stimulation of the kidney cell, and was independent of circulatory effects. Barcroft and Straub (2) also favored the secretion theory since they found that caffeine and urea increased the metabolism of the kidney of the rabbit and cat during the period of diuresis. However, Hayman and Schmidt (3), using caffeine, were unable to confirm these results. Richards and Plant (4), working with the kidney kept alive by a special form of perfusion, found that caffeine produced a diuresis when the kidney blood flow and volume remained constant. Cushny and Lambie (5) studied the effect of the intravenous injection of caffeine, urea and strophanthin on the change in per minute blood flow through the kidney of the rabbit. They found that caffeine and urea produced a short stage of acceleration of blood flow, soon followed by a return to normal rate, while the diuresis persisted. Under the same conditions small doses of strophanthin produced no appreciable change in blood flow and had no diuretic effect, larger doses decreased the blood flow through the kidney and diminished the urine output. They concluded that the diuretic action of caffeine and urea was independent of any change in blood supply. They believed that caffeine caused diuresis by reducing the resistance to filtration through the glomerular capsule, by a specific action on its cells, and that urea acted by increasing the osmotic resistance to the re-absorption of filtrate in the tubules.

1 This investigation was aided by a grant from the Proctor Fund for the study of chronic disease, Harvard Medical School. 
Loewi, Fletcher and Henderson (6) opposed the secretion theory of Von Schroeder and held that the primary action of caffeine was one of renal vasodilatation, which tended to increase filtration through the capillaries. Phillips and Bradford (7), Gottlieb and Magnus (8) and Starling (9), while studying changes in kidney volume by means of the oncometer, found that caffeine diuresis was accompanied by a persistent and marked expansion. However, as Cushny has suggested, the kidney volume depends not only on the calibre of the blood vessels, but also on the contents of the renal tubules and the amount of lymph in the interstices. Variations in any or all of these factors would tend to influence the oncometer readings.

Hayman and Starr (10), in estimating the number of functioning glomeruli in the rabbit's kidney by intra-vital staining methods, found that during the action of caffeine all glomeruli were open. This work has been substantiated by that of Richards and Schmidt (11), who showed, while observing directly the circulation through the glomeruli in the frog's kidney, that the number of active glomeruli and the degree of activity were increased by caffeine. This would tend to increase the capillary surface and hence the extent of the filtering bed.

Spiro and Vogt (12) found that, in addition to a diuretic action, caffeine produced a marked increase in lymph flow through the thoracic duct. They assumed that the drug had an action on tissue exchange which was independent of the renal action. Spiro (13) studied the effect of theocine on rabbits and found that a single large dose produced first a polyuric and later an oliguric stage. During the polyuric stage there was a decrease in the sodium chloride per cent in both the urine and blood, and the water content of the blood was lessened. During the oliguric stage the concentration of the blood gradually returned to normal. In nephrectomized animals the drug produced an absolute decrease in water and chloride content of the blood. He concluded that the purine bases, as well as having an action on the kidney, also had a direct effect on tissue exchange, by means of which the tissues took up water and sodium chlorid from the blood.

Ellinger, Heymann and Klein (14) recently advanced a chemical theory in which they held that the purine derivatives decreased the affinity of the plasma proteins for water and thus favored filtration through the glomeruli. This view, however, has received little support.

Many investigators believe that the diuretic action of mercury is dependent on changes in the blood or tissues, some support the theory of a direct renal action, while others hold that both factors exist. The work of Govaerts (15) strongly favors the theory of a direct action on the kidney. In one group of experiments the kidney from a dog at the height of novasurol diuresis was transplanted to the neck of a normal dog, anastomosing the renal artery to the carotid artery, and the renal vein to 
the jugular vein. At the completion of anastomosis an abundant urine, seven to one hundred times greater than that from the normal kidney in situ, was obtained. This urine had all the characteristics of novasurol urine. In another group of experiments a kidney from a normal dog was transplanted to the neck of an animal at the height of novasurol diuresis; the urine output from the neck kidney was ten to one hundred times less than that from the novasurolized kidney in place. The urine from the transplanted kidney was highly colored and lacked the characteristics of novasurol urine. From these experiments Govaerts concluded that the action of novasurol was primarily on the kidney. Schmidt (16) perfused the frog's kidney with small doses of novasurol and found that the drug produced a distinct diuresis. Gremels (17), using the heart-lung preparation of Starling and Verney in irrigating the dog's kidney, found that if he added to the blood of such a preparation 0.01 to 0.04 gram of novasurol or 0.025 gram of salyrgan a marked diuresis was produced, and this without change in the volume blood flow through the kidney. Melville and Stehle (18), believing that novasurol was only indirectly active through its decomposition products, made use of mercuric chloride. They used dogs, injecting the drug into one renal artery and measuring the urine output from both kidneys. The resulting diuresis began simultaneously from both sides, and in some instances the output from the injected kidney was diminished. They concluded that mercury produced its diuretic effect through an extra-renal action. Several German investigators, including Nonnenbruch (19), Tezner (20), Saxl and Heilig (21) and Bohn (22), believe novasurol to act largely on the tissues and plasma colloids.

Since the introduction of digitalis into medical therapeutics there has been considerable controversy regarding its diuretic action. Some believe that the drug has a direct effect on the kidney and its vessels, while others hold that diuresis is the result of an improved general circulation. Reinike (23) investigated the action of digitalis on the rabbit's kidney by administering the drug to a group of animals over a long period of time. $\mathrm{He}$ found the kidneys of these animals to be larger than those of a control series and suggested that under the influence of the drug the kidneys had undergone excessive activity. Phillips and Bradford (7) found that digitalin produced a decided increase in urinary flow when administered to the $\mathrm{dog}$; this was accompanied by a peripheral vascular constriction as indicated by the oncometer. Strophanthin had little effect either on the vessels of the kidney or the urinary output. Kasztan (24) perfused the kidney of the dog, cat and rabbit with Ringer's solution. When small doses of strophanthin were added to the circulation, arterial dilatation took place; larger doses caused constriction. He concluded that strophanthin had a peripheral effect on the vessels of the kidney. Fahrenkamp (25) obtained identical results using digitoxin in place of strophanthin. Gremels, 
whose work has been referred to, concluded that strophanthin and digitoxin had an action on the renal parenchyma quite separate from that on the peripheral vessels.

The following experiments were performed on dogs in the laboratory of the Department of Medicine of Harvard Medical School, at the suggestion and under the supervision of Dr. Henry A. Christian, Hersey Professor of the Theory and Practice of Physic in Harvard University. The object of the work was to study the effect of the injection of diuretics in varying dosage into one renal artery. It was felt that, if the diuretic had a direct action on the renal parenchyma, a dose sufficiently small should produce a diuresis from the injected kidney and leave the opposite kidney unaffected (since it could not reach the other organ in the same concentration); a slightly larger dose should produce a bilateral effect, manifested earlier and being more marked on the injected side, while a still larger dose might shut down the injected kidney and from the other induce a diuresis.

\section{EXPERIMENTAL METHODS}

The dogs used in this work were healthy young animals. They were allowed water but deprived of food for a period of eighteen hours prior to the beginning of the experiment.

Anesthesia was induced by the intraperitoneal injection of dial "Ciba" 2 with urethane, in doses of $0.65 \mathrm{cc}$. per $\mathrm{kgm}$. of body weight. This dosage was sufficient to cause complete anesthesia in 20 to 30 minutes, the effect persisting throughout the duration of the experiment. Only rarely was it necessary to use additional small doses of dial. The animal was placed on a warm padded operating table. The abdomen was opened by a low midline incision and the bladder delivered to the surface. The ureters, at the point of entry into the bladder, were isolated and dissected free for a distance of approximately $1 \mathrm{~cm}$. A small incision was made into each ureter at an avascular point and flexible ureteral catheters of equal diameter inserted. These were held in place and leakage prevented by a ligature of number 0 chromic catgut. The bladder was emptied and returned. The peritoneum, the muscle wall and the skin were approximated in three layers, by a continuous suture of black silk, allowing the distal ends of the catheters to escape from the lower part of the incision. The above procedure usually required twenty to thirty minutes.

Urine was collected from each catheter into graduated cylinders and measured at half-hourly intervals. Hydremia was maintained by the intravenous injection of 100 to $200 \mathrm{cc}$. of 0.9 per cent $\mathrm{NaCl}$ solution every thirty minutes. The solution was warmed to body temperature and injected slowly from a $100 \mathrm{cc}$. syringe at the rate of $50 \mathrm{cc}$. per minute into one of the leg veins.

Because of the relative ease in exposure, the left renal artery was chosen for injection of the diuretic. With the animal on the right side, an infracostal incision was made through the skin and muscles of the left flank. The peritoneum was gently drawn aside and the renal artery isolated, care being taken

${ }^{2}$ We wish to express our thanks and appreciation to the Ciba Company, Greenwich and Morton Streets, New York City, for supplying us with the anesthetic used in this work. 
to avoid undue trauma to the nerves running along the artery, to the renal vein and the ureter. The artery was supported by a loosely held ligature of number $O$ catgut. The diuretic was injected slowly through a small needle, on the withdrawal of which bleeding was controlled by light pressure with a gauze pack. During injection the blood supply to the kidney was disturbed as little as possible, and at no time was shut off for more than a fraction of a minute. The muscles and skin were approximated with a continuous suture of black silk.

The duration of each experiment was $5 \frac{1}{2}$ to 6 hours, a control period of $2 \frac{1}{2}$ to 3 hours preceding the injection of the diuretic. At the termination of the experiment the animal was sacrificed, and the catheters and ureters examined in order to rule out any factors which might interfere with urine flow.

Examination of the urine included specific gravity determinations, and estimation of albumin by the Heller test.

\section{RESULTS}

This study included eighty-two experiments from which typical examples have been selected as illustrative of the action of each diuretic used.

Since the experiments were acute in nature, it was necessary to study the relation of the anesthetic to urine output. In Figure 1 the results of the intravenous injection of $200 \mathrm{cc}$. of 0.9 per cent $\mathrm{NaCl}$ solution every half-hour upon the rate of urine excretion in (a) the normal unanesthetized $\mathrm{dog}$, and (b) the dog anesthetized by the intraperitoneal injection of dial are well shown. In the normal dog an enormous diuresis was produced, whereas in the anesthetized animal the output at hourly intervals never exceeded $40 \mathrm{cc}$. This depicts the inhibitory rôle played by the anesthetic throughout these experiments.

Figure 2 shows the results obtained by the injection directly into the left renal artery, of small doses of the organic mercury compounds (salyrgan and novasurol). With the dosage used, the injected kidney showed a very definite and prompt diuresis, while the output of the opposite kidney did not increase. In the experiment with novasurol, shown in the upper set of curves, there was difficulty in exposing the main artery, only one of the two branches could be injected. This undoubtedly explains the relatively slight diuretic effect. The response to slightly larger doses is illustrated in Figure 3 . It is noted that both kidneys showed a well marked diuresis, which was earlier in onset and more profuse from the injected side. Figures 4 and 5 present the results of still larger doses, with these dosages the output of the injected kidney was diminished, while that of the opposite side was increased enormously. The observations with theocine-sodium-acetate are shown in Figure 6, the response to this drug resembled in kind but was less marked than that with the mercury compounds. In the experiments in which small doses of salyrgan, novasurol and theocine-sodium-acetate were used, the urine from the injected kidney was pale in color, of a low specific gravity and showed albumin, while that from the opposite kidney remained well colored, of a 


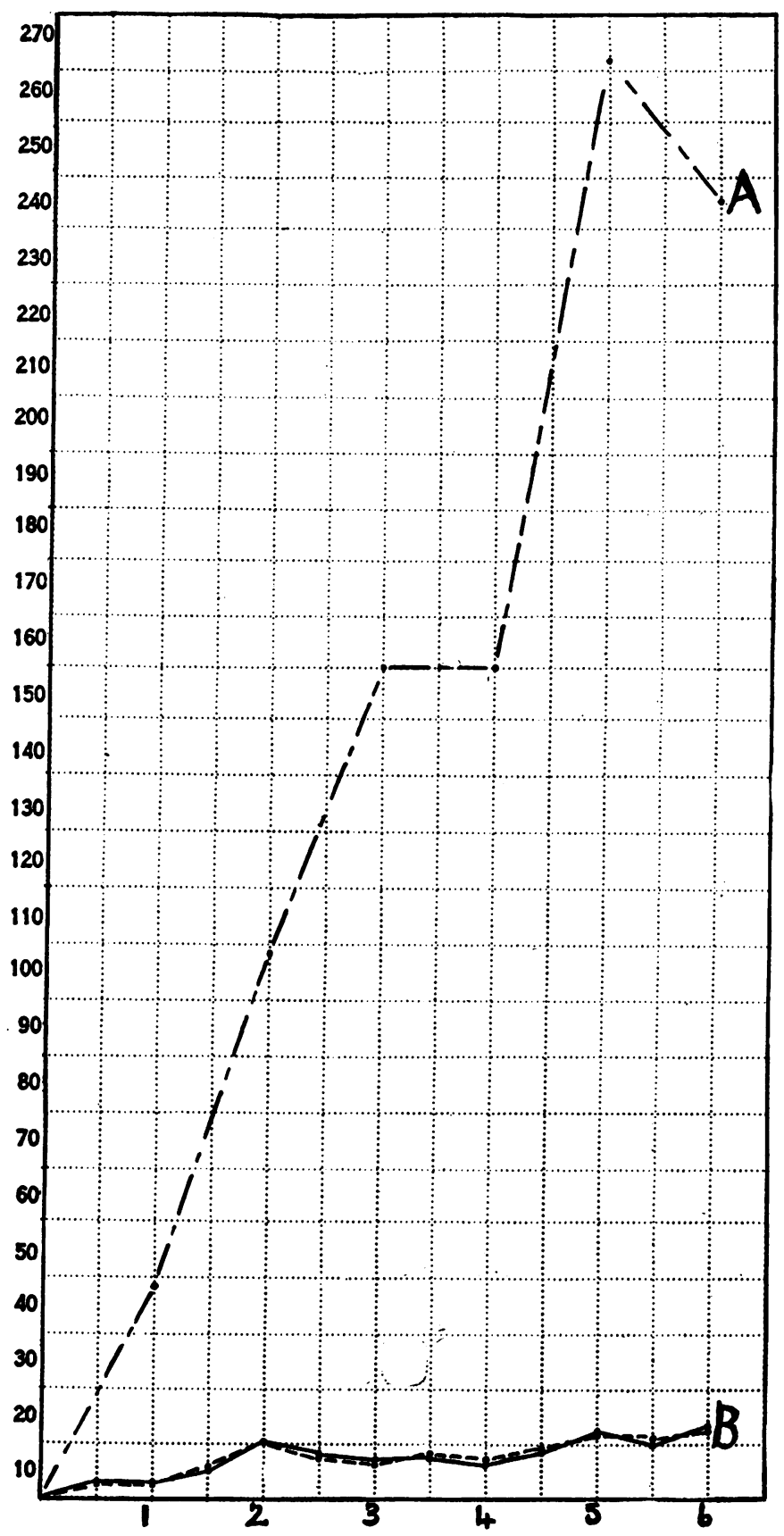

FIG. 1. $A$. Unanesthetized dog, urine output in cc. per hour. B. Anesthetized dog, solid line shows urine output in cc. per half hour from left kidney; broken line shows urine output in cc. per half hour from right kidney. 


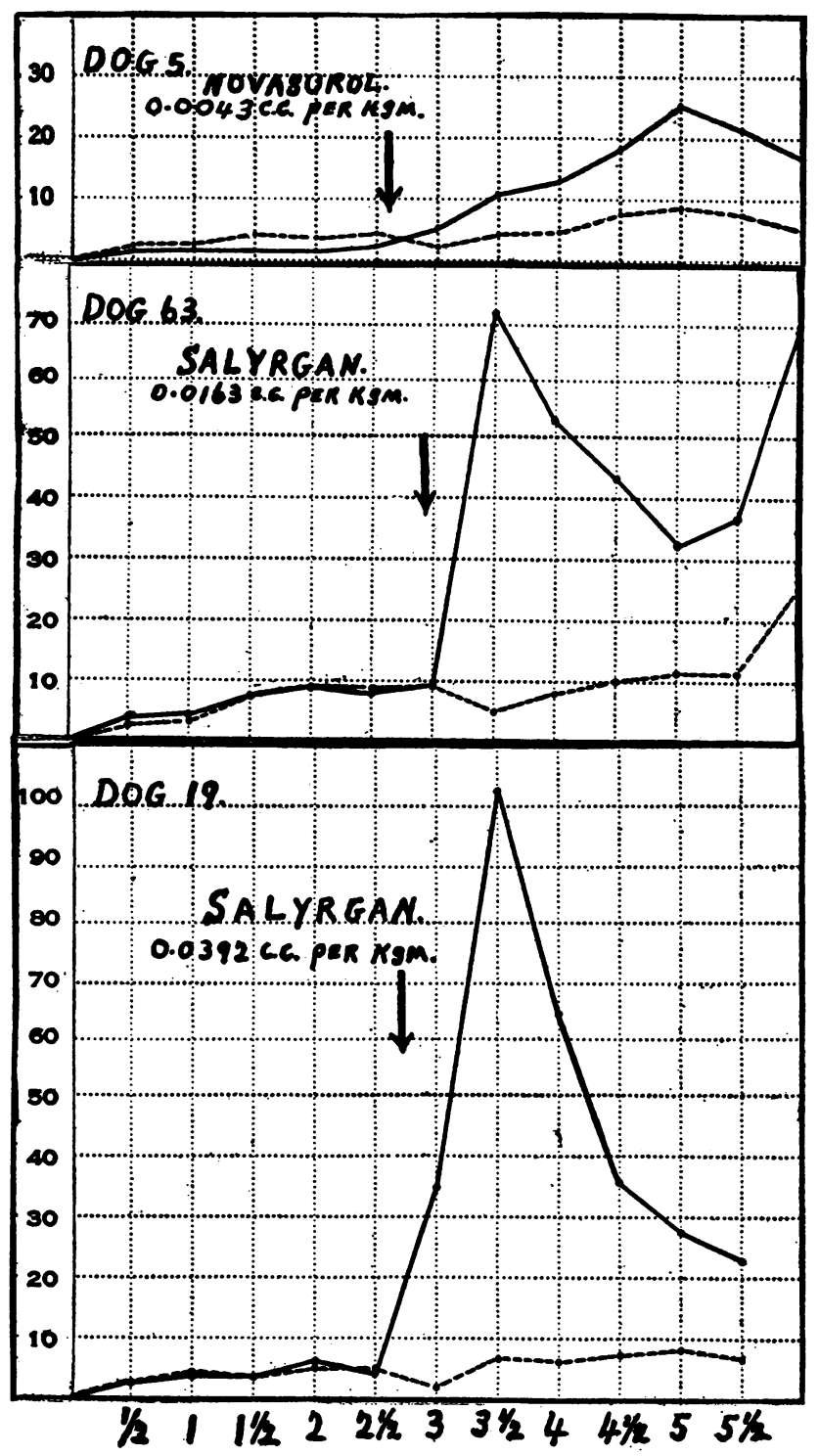

FIG. 2. Solid line shows urine output in cc. per half hour from left kidney (injected kidney); broken line shows urine output in cc. per half hour from right kidney. Arrow indicates injection of diuretic. 
1204

EFFECT OF DIURETICS

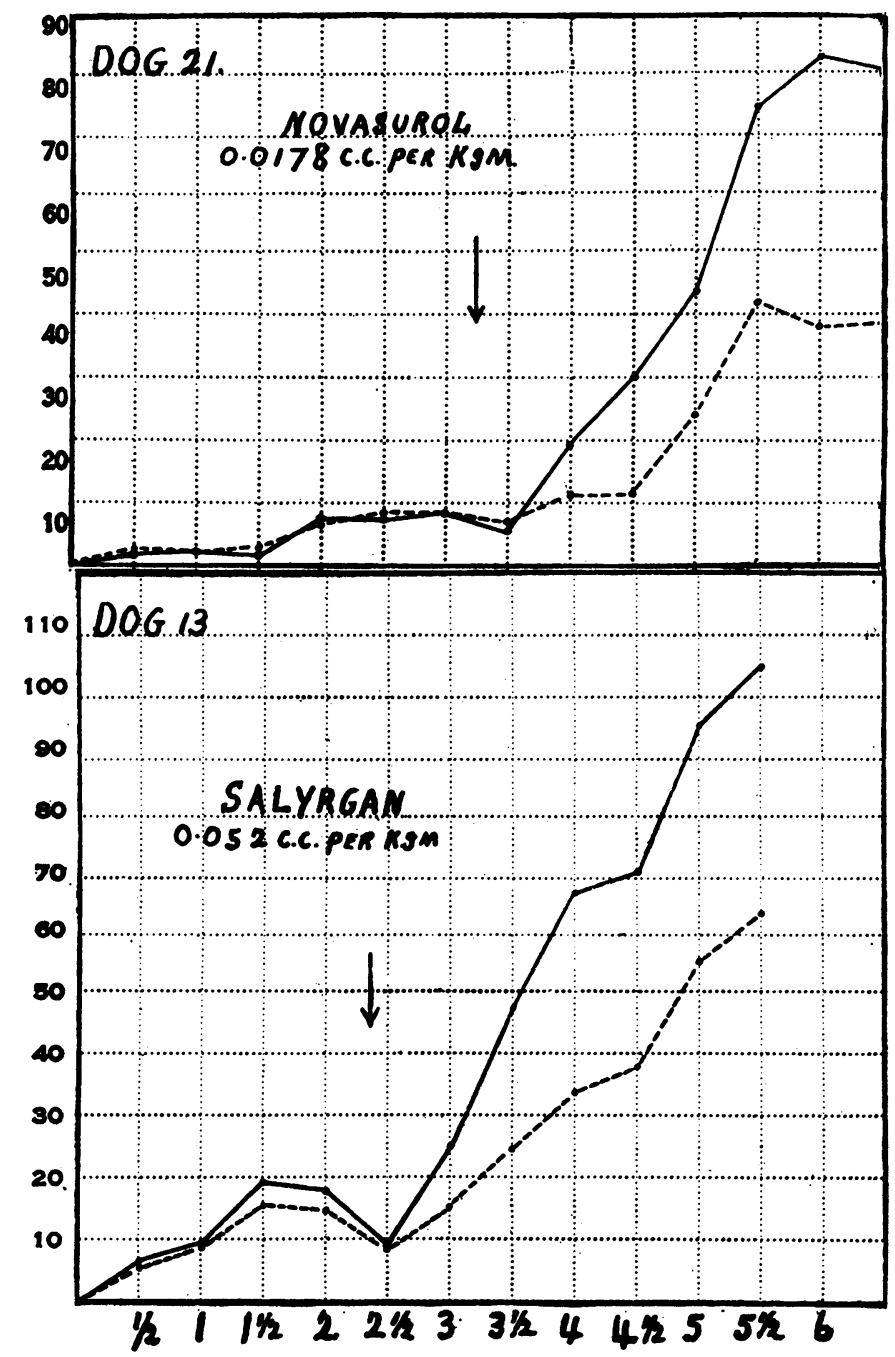

FIG. 3. Solid line shows urine output in cc. per half hour from left kidney (injected kidney); broken line shows urine output in cc. per half hour from right kidney. Arrow indicates injection of diuretic. 


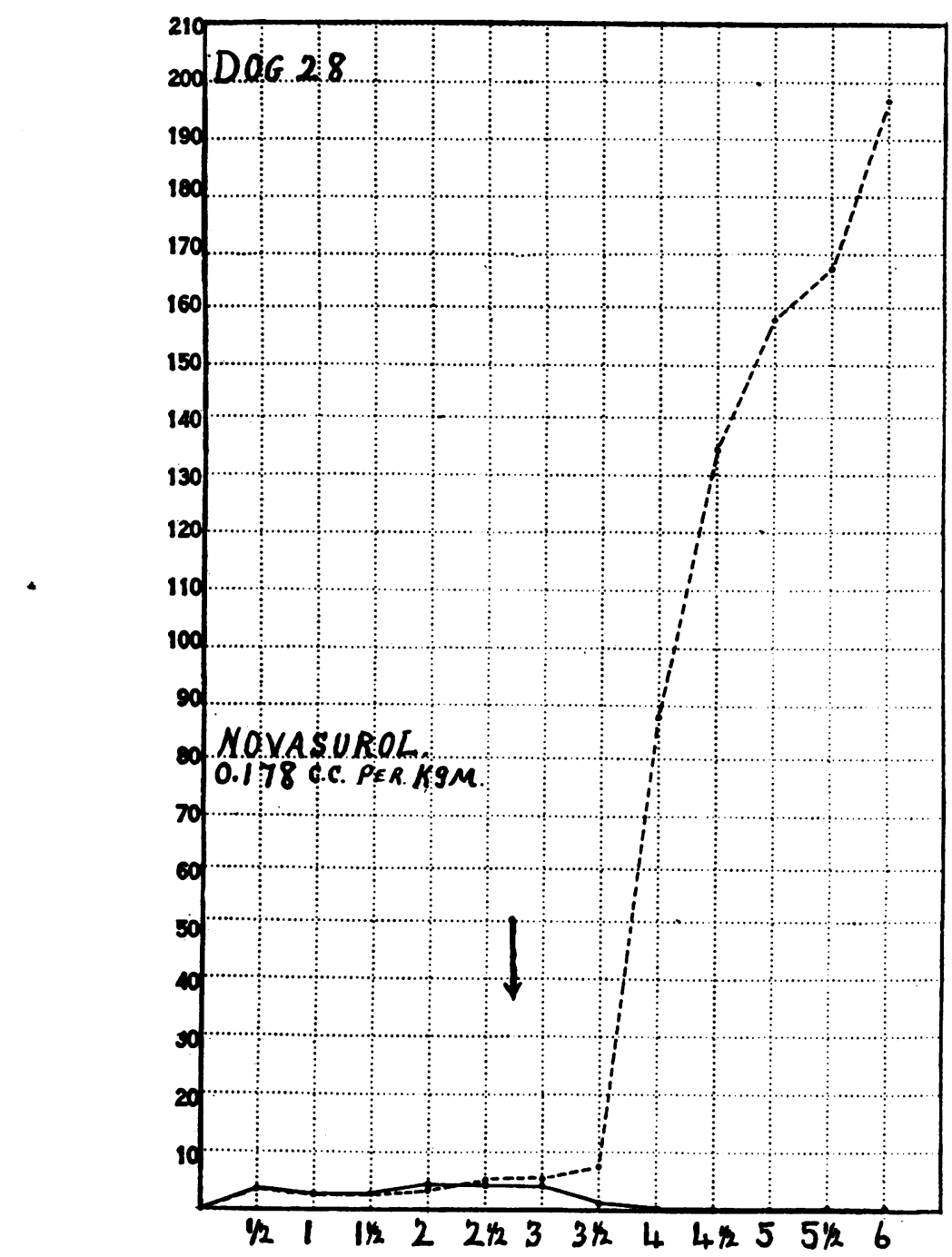

FIG. 4. Solid line shows urine output in cc. per half hour from left kidney (injected kidney); broken line shows urine output in cc. per half hour from right kidney. Arrow indicates injection of diuretic. 


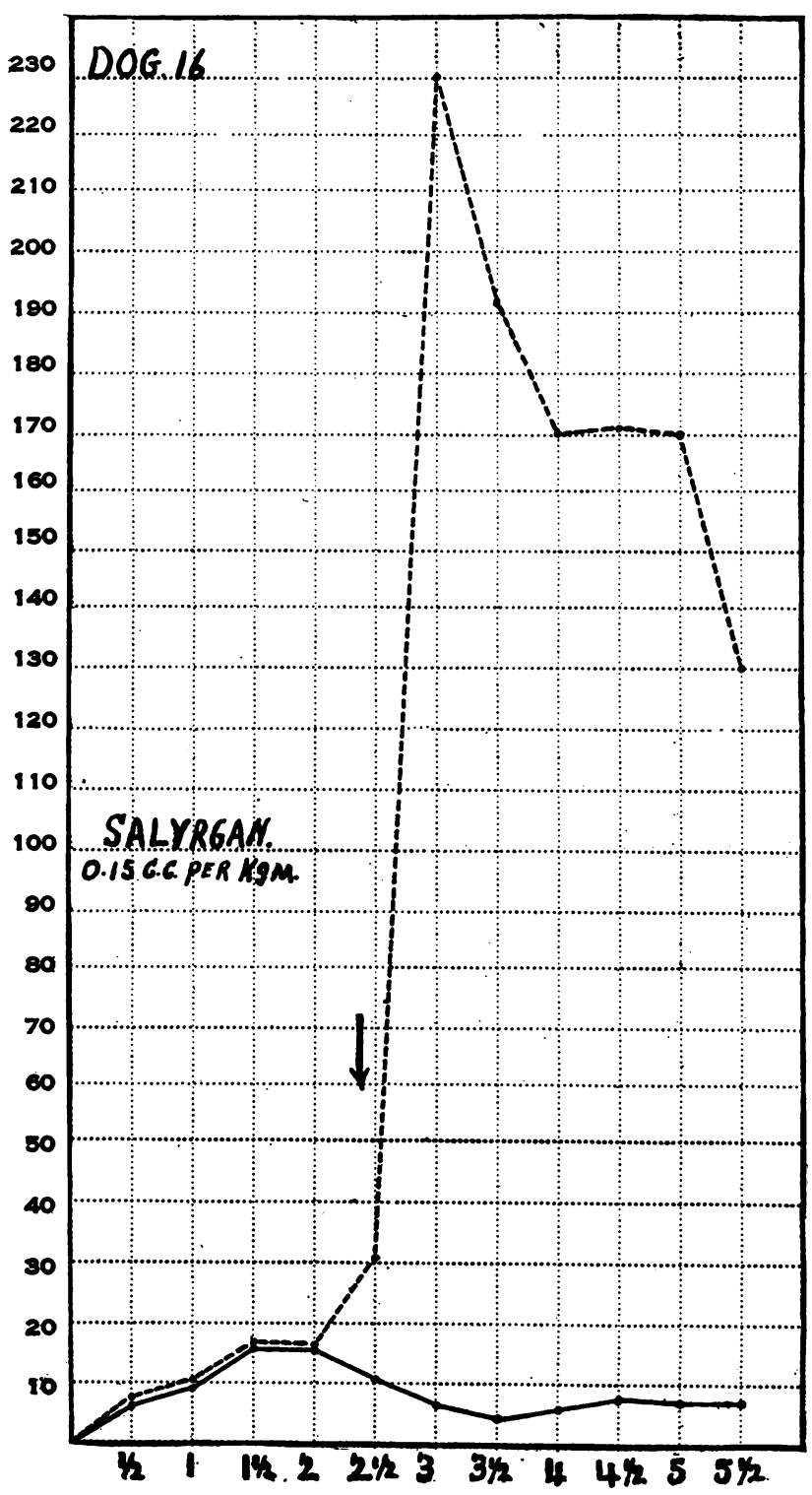

FIG. 5. Solid line shows urine output in cc. per half hour from left kidney (injected kidney); broken line shows urine output in cc. per half hour from right kidney. Arrow indicates injection of diuretic. 


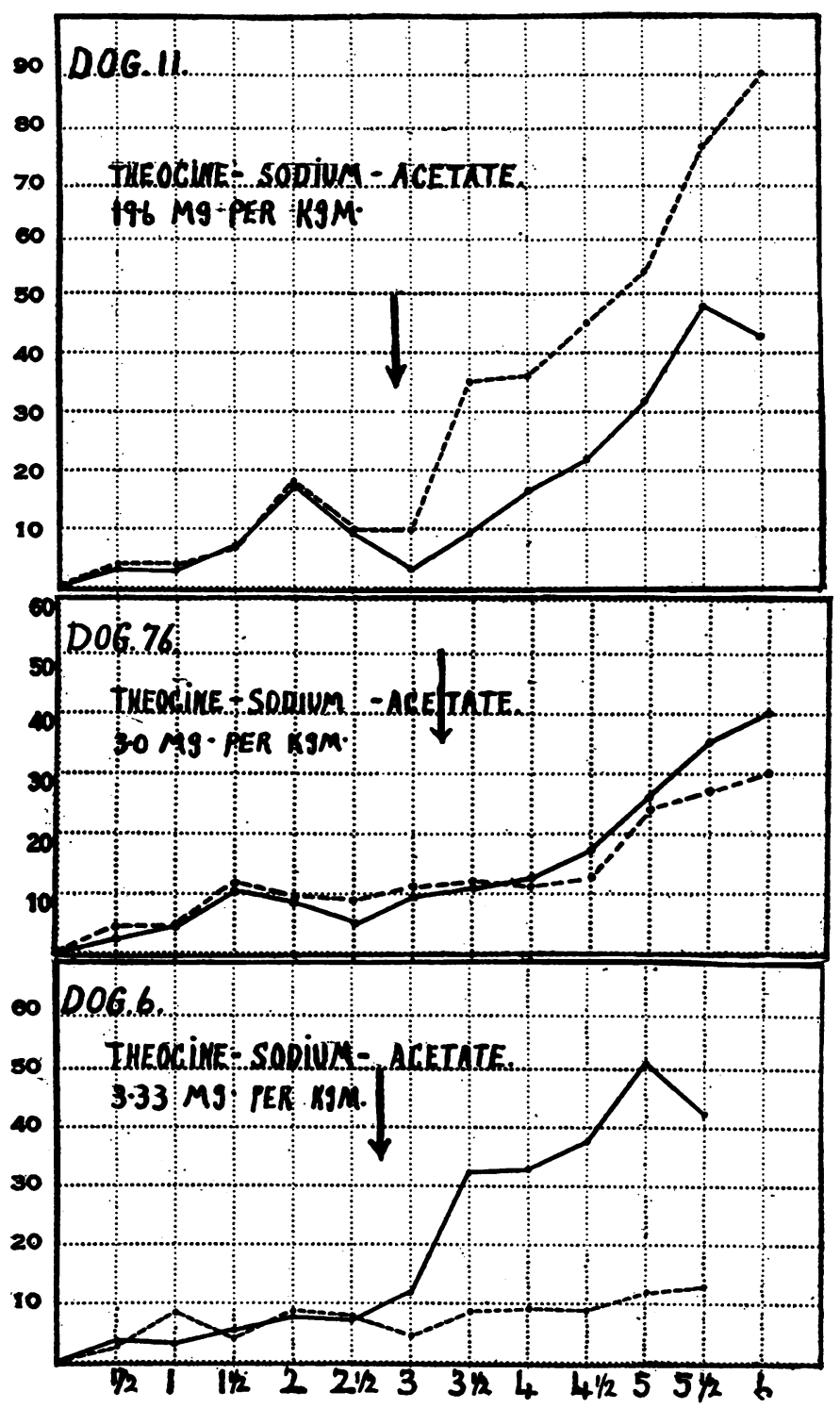

FIG. 6. Solid line shows urine output in cc. per half hour from left kidney (injected kidney); broken line shows urine output in cc. per half hour from right kidney. Arrow indicates injection of diuretic. 


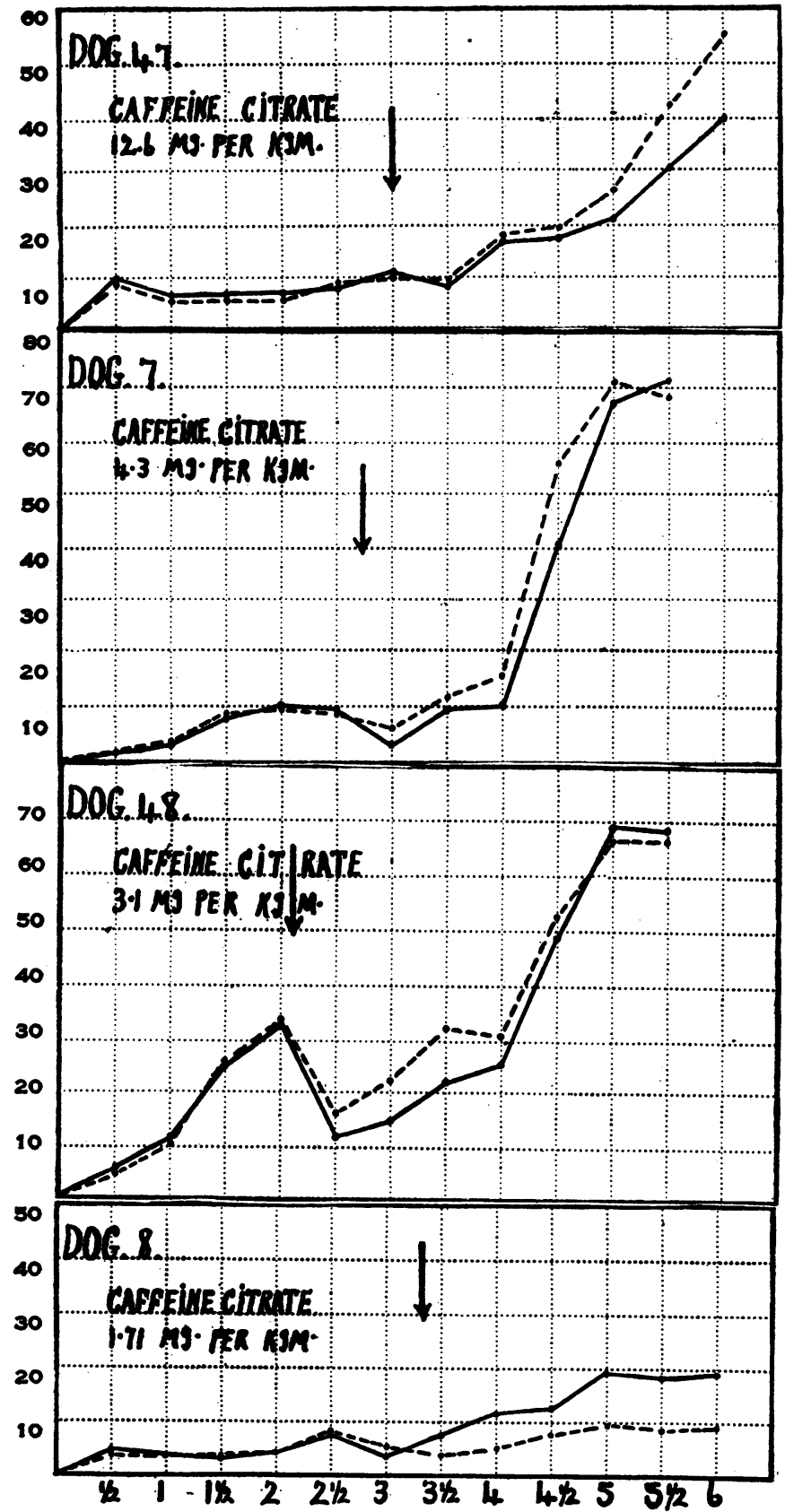

Fig. 7. Solid line shows urine output in cc. per half hour from left kidney (injected kidney); broken line shows urine output in cc. per half hour from right kidney. Arrow indicates injection of diuretic. 

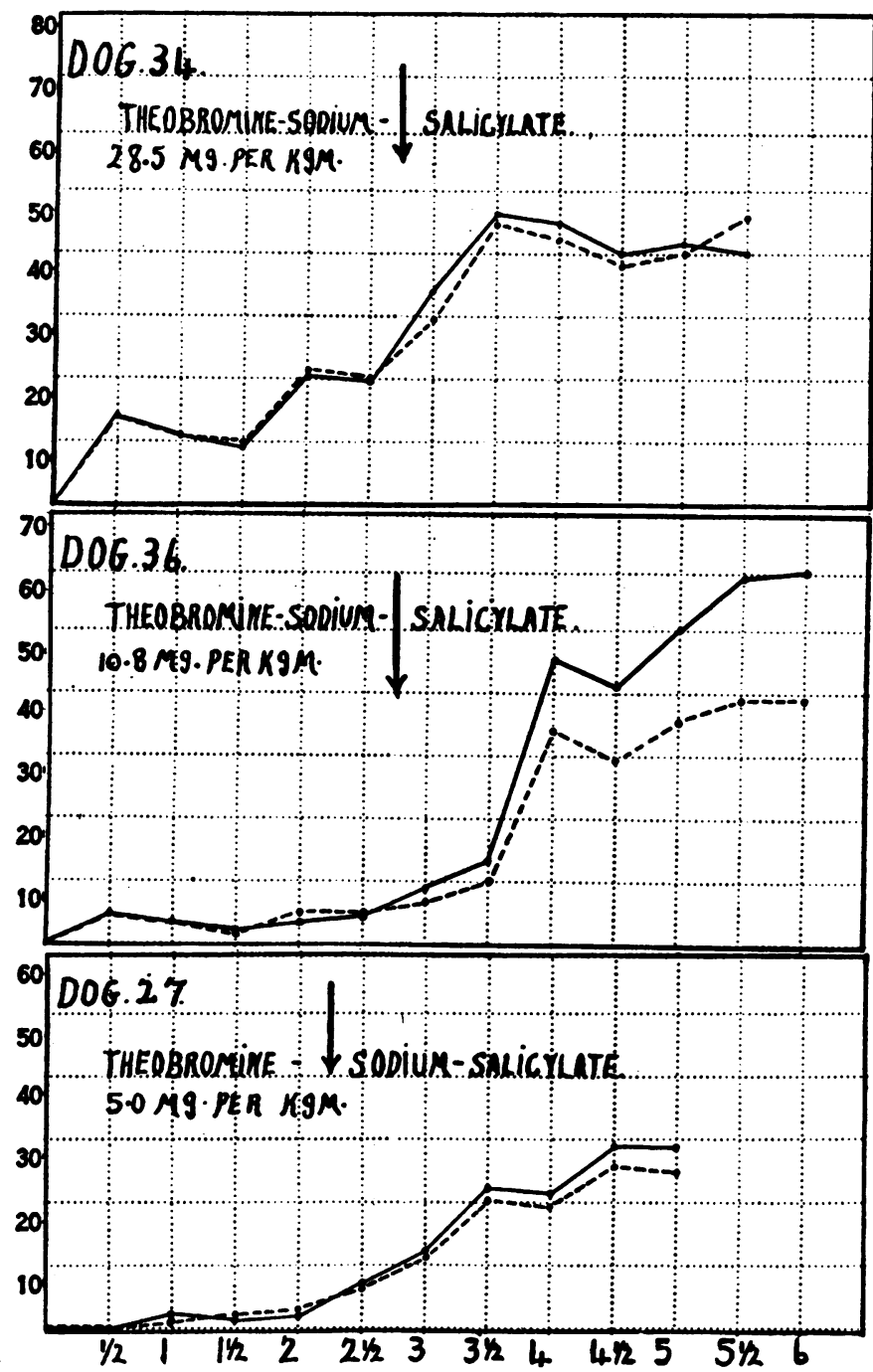

FIG. 8. Solid line shows urine output in cc. per half hour from left kidney (injected kidney); broken line shows urine output in cc. per half hour from right kidney. Arrow indicates injection of diuretic. 


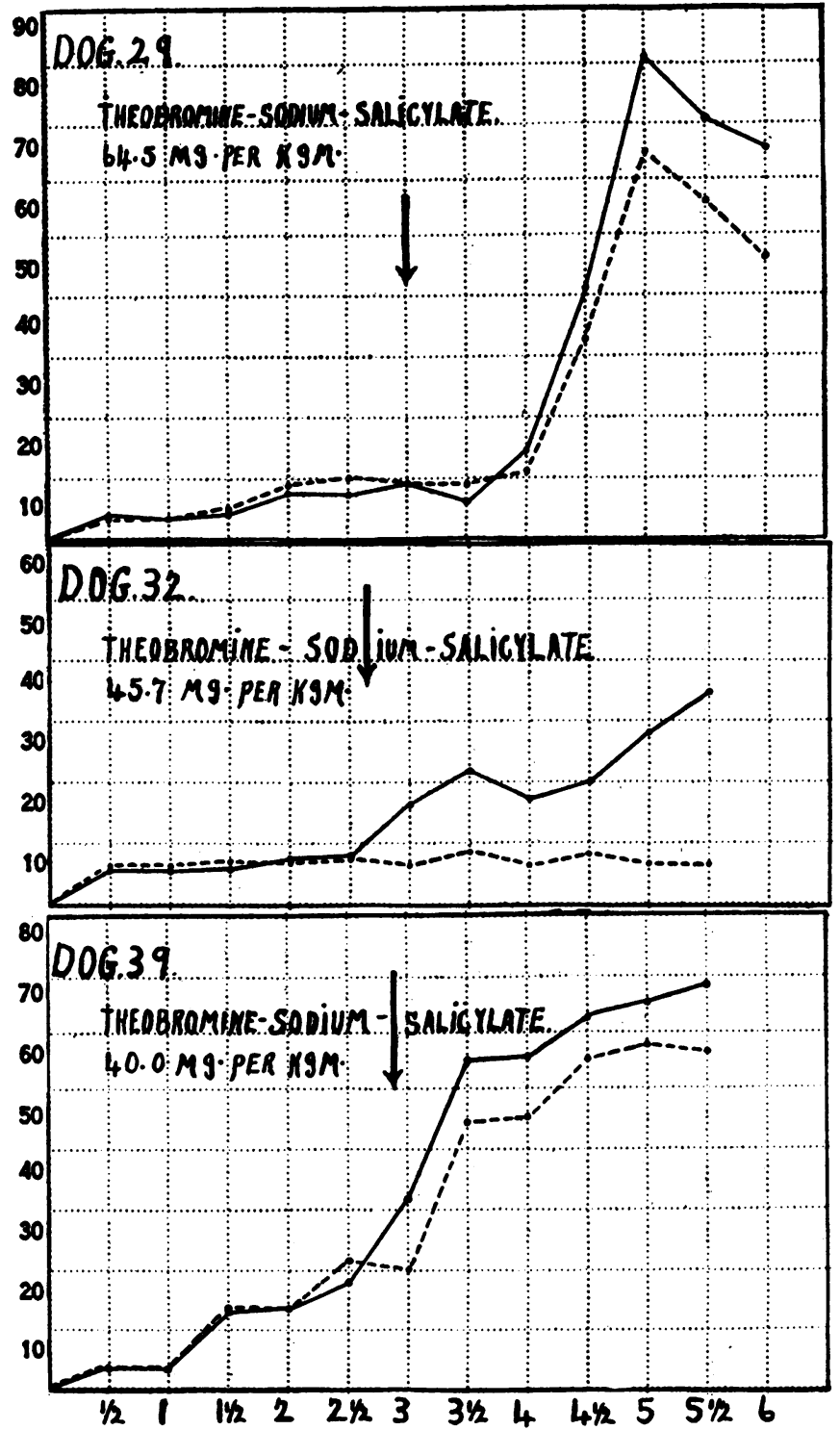

FIG. 9. Solid line shows urine output in cc. per half hour from left kidney (injected kidney); broken line shows urine output in cc. per half hour from right kidney. Arrow indicates injection of diuretic. 
considerably higher specific gravity, and showed no albumin or only the slightest possible trace. With larger doses of the same diuretics the urines from both kidneys were indentical in color and specific gravity, but that from the injected kidney showed relatively more albumin.

Figures 7 to 13 indicate the results observed with the injection of varying doses of caffeine-citrate, theobromine-sodium-salicylate, ${ }^{3}$ theophylline-ethylene-diamine, ${ }^{4}$ theophylline-calcium-salicylate and urea.

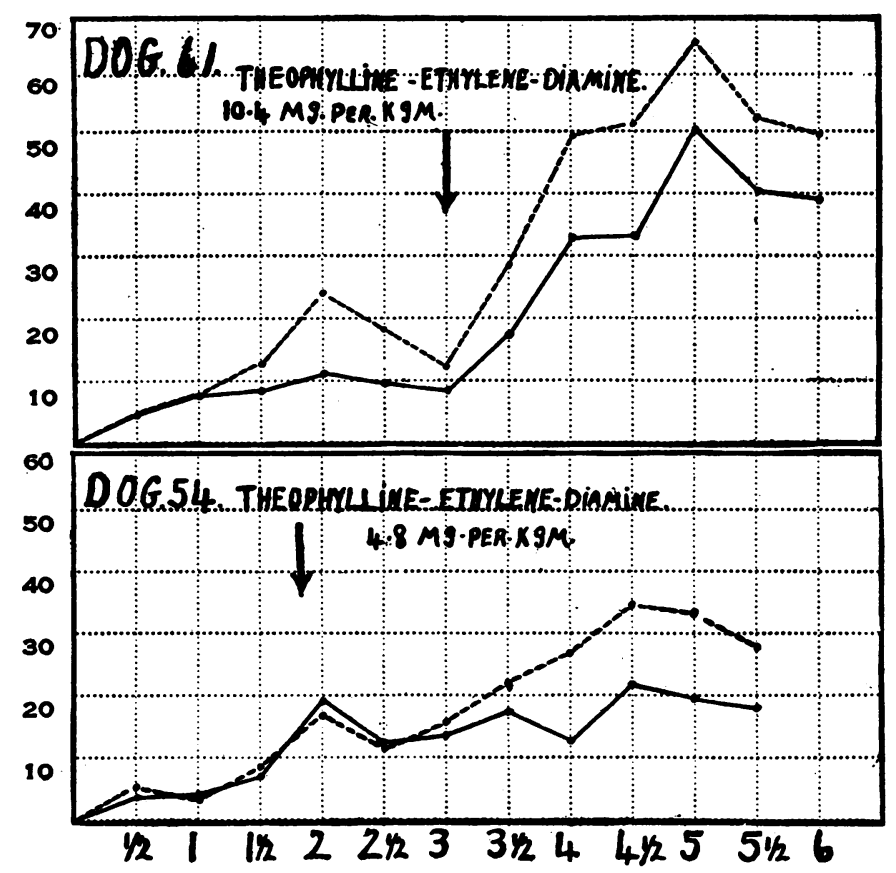

FIG. 10. Solid line shows urine output in cc. per half hour from left kidney (injected kidney); broken line shows urine output in cc. per half hour from right kidney. Arrow indicates injection of diuretic.

It is noted that this group of diuretics produced a bilateral response, the time interval between injection and onset of diuresis showing little difference as regards the two kidneys. In some of these experiments diuresis commenced a few minutes after injection of the diuretic, in others a considerable latent period was noted. The effect of digitan is shown in

8 We wish to express our thanks and appreciation to Bilhuber-Knoll Corporation, 154 Ogden Avenue, Jersey City, New Jersey, for supplying us with theobromine-sodium-salicylate (diuretin) and theophylline-calcium-salicylate (phyllicin) used in these experiments.

4 We wish to express our thanks and appreciation to A. W. Kretschmar, Inc., 396-398 Broadway, New York City, for furnishing us with theophylline-ethylene-dia mine (thephyldine) used in this work. 


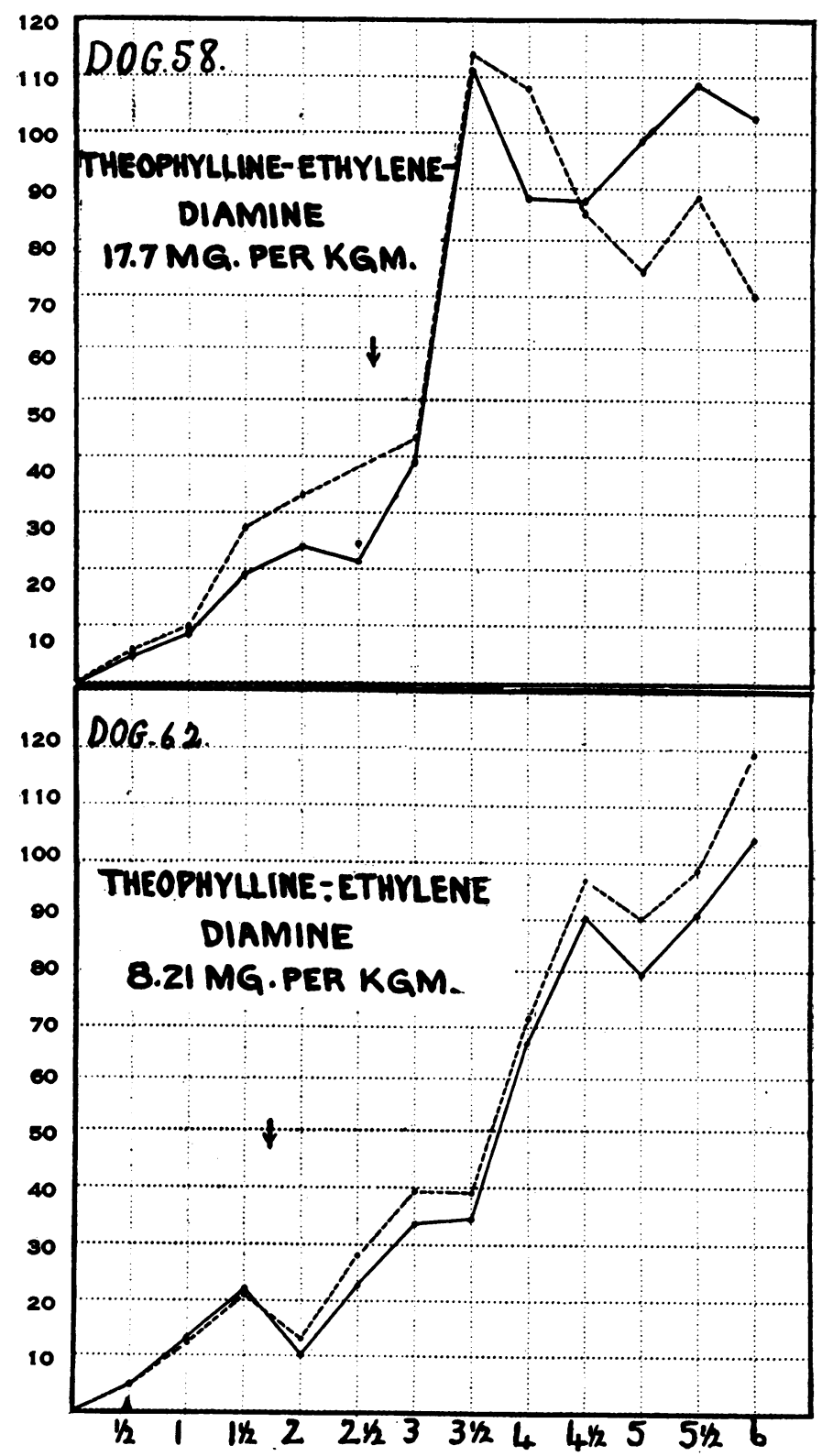

FIG. 11. Solid line shows urine output in cc. per half hour from left kidney (injected kidney); broken line shows urine output in cc. per half hour from right kidney. . Arrow indicates injection of diuretic. 
Figure 14. A bilateral diuresis occurred, but the output of the injected kidney was relatively less, particularly when larger doses of the drug were used. In this group of experiments the urines from the two kidneys were practically identical during the period of diuresis. They were alike in color, of an equal specific gravity, and showed similar amounts of albumin (slightest possible trace to very slight trace).

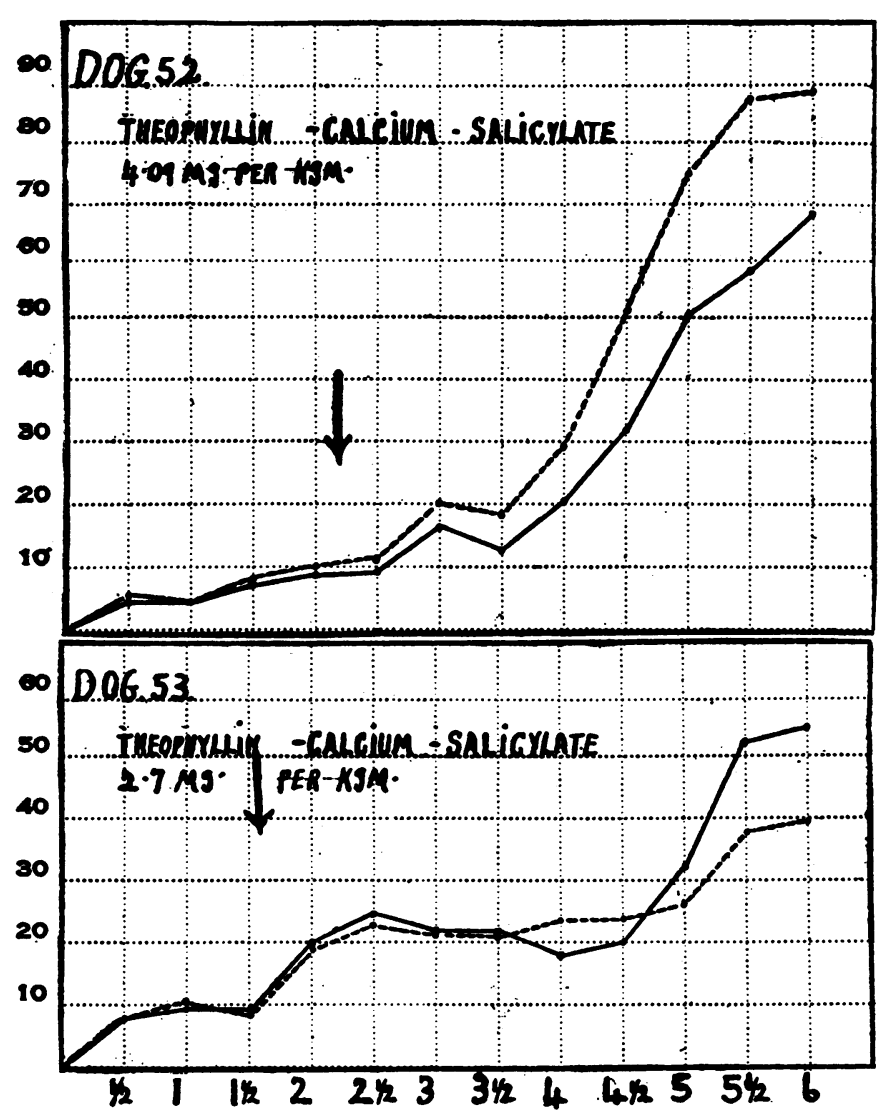

FIG. 12. Solid line shows urine output in cc. per half hour from left kidney (injected kidney); broken line shows urine output in cc. per half hour from right kidney. Arrow indicates injection of diuretic. 


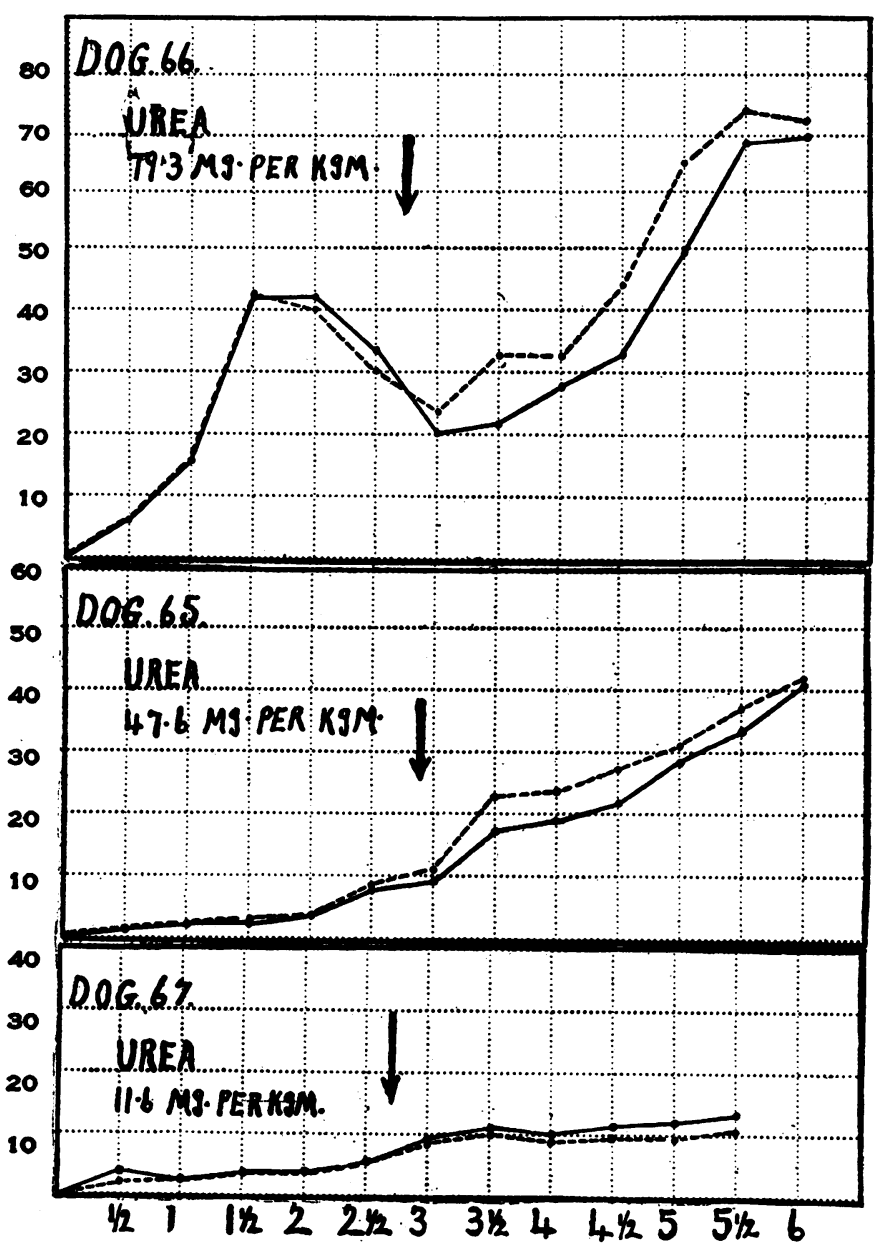

FIG. 13. Solid line shows urine output in cc. per half hour from left kidney (injected kidney); broken line shows urine output in cc. per half hour from right kidney. Arrow indicates injection of diuretic. 
EDWARD A. BARTRAM

1215

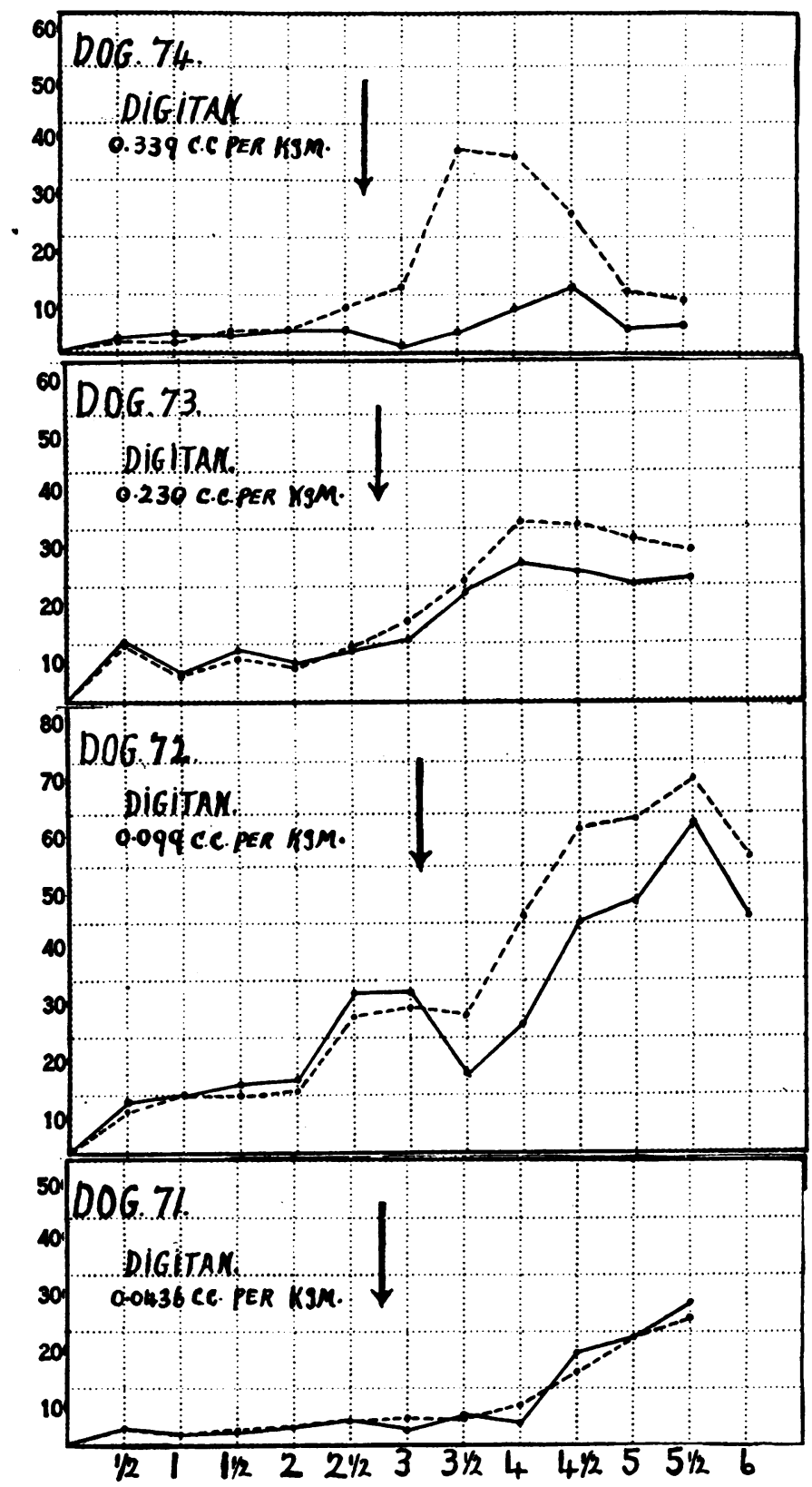

Fig. 14. Solid line shows urine output in cc. per half hour from left kidney (injected kidney); broken line shows urine output in cc. per half hour from right kidney. Arrow indicates injection of diuretic. 


\section{DISCUSSION}

Von Schroeder (1), who first investigated the diuretic action of the purine group, came to the conclusion that the dog's kidney was refractory to caffeine, since he failed to obtain a diuretic response. Wallace and Pellini (26), working with dogs in a state of water balance, and nitrogen and salt equilibrium, found that the caffeine group actually diminished the daily urine output. However, a review of their experiments shows that the urine was collected by catheterization at twenty-four hourly intervals. It seems quite possible that although the daily urine output was diminished, there may have been a period of diuresis with subsequent oliguria, in which case the total output for the day might not necessarily be increased. Loeb (27) also was unable to obtain a definite diuresis by administering caffeine to the normal dog, but noted that when hydremia and diuresis were induced by a constant infusion of saline solution, the secretion of urine was increased to a marked degree.

In our experiments hydremia was maintained by the intravenous injection of 100 to $200 \mathrm{cc}$. of 0.9 per cent $\mathrm{NaCl}$ solution every half-hour. That a good deal of this fluid was stored in the tissues there is little doubt, for as Bogert, Underhill and Mendel (28) have shown, complete restoration of original blood volume in the rabbit and dog, takes place in thirty minutes after the intravenous injection of a quantity of saline solution equal to the calculated blood volume of the animal. They estimated also that the capacity of the tissues of the rabbit to absorb fluid was four times the normal blood volume of the animal.

In the normal dog this amount of saline solution should induce an enormous diuresis, probably as Cushny has suggested by dilution of the plasma proteins, which results in a more profuse filtration through the glomeruli. However, in our experiments which were conducted not on the normal dog, but on the dog subjected to prolonged anesthesia, a dilution diuresis appears to have played an insignificant part. This is probably attributable to the inhibitory action of the anesthetic, an action which has been observed by many workers, and one which seems impossible to overcome in acute animal experimentation. Fee (29) has shown that water diuresis in decerebrate dogs is markedly diminished by the administration of various anesthetics, the inhibition lasting for the same length of time as the narcotic effect. Ogden (30) made similar observations, using as an anesthetic full doses of amytal by the intraperitoneal route. This inhibitory action is well shown in Figure 1, where the infusion of $200 \mathrm{cc}$. of 0.9 per cent $\mathrm{NaCl}$ solution at half-hour periods in the normal dog gave rise to a marked diuresis, whereas the dog under dial anesthesia showed a constant output with no tendency to diuresis. In a few other experiments, particularly with the purine group of diuretics, where for some reason or other the diuretic failed to act, the same more or less constant urine output continued throughout the duration of the 
experiment, there being little tendency to diuresis from the injected saline. These observations justify the assumption that the diuretic effects obtained in our experiments were precipitated by the injection of the diuretic, and were not the result of a spontaneous diuresis from the injected saline solution, although the latter may have augmented the diuretic effect of the former.

From our experimental results we feel justified in dividing the diuretics used in this work into two main groups, (1) those that appear to exert their primary effect by a direct action on the renal parenchyma, and (2) those that appear to have a different and possibly an extra-renal action.

Included in the first group are the organic mercury compounds (novasurol and salyrgan), also one of the xanthine derivatives (theocinesodium-acetate). When small doses of novasurol and salyrgan are injected directly into one kidney an immediate and well marked diuresis ensues from the injected side, the urine immediately changes from one of high color to one of pale color, shows albumin and has a lower specific gravity, whereas the urine from the opposite kidney retains its color, shows no albumin and no change in specific gravity. Slightly larger doses induce a bilateral diuresis, more marked and earlier in onset from the injected side, the urines from both kidneys being pale and of an equally low specific gravity, that from the injected kidney showing more albumin. Still larger doses shut down the injected kidney and produce a marked diuresis from the opposite side, the urine from the injected kidney showing a considerable amount of albumin (slight trace to trace). The probable explanation of these results is that salyrgan and novasurol induce diuresis by a direct action on the renal parenchyma, possibly involving the tubules with resulting decreased absorption. The action of theocine-sodium-acetate is similar to that of the mercurial drugs, although the diuretic effect is less marked.

The second group includes caffeine-citrate, theobromine-sodiumsalicylate, theophylline-ethylene-diamine, theophylline-calcium-salicylate, urea and digitan. The injection of any of these diuretics in varying doses results in a bilateral diuresis, beginning in some instances a few minutes after injection, in others after a latent period has intervened. Both kidneys respond to about the same degree, and the urines from both sides are identical. It is noted that in the experiments in which theobrominesodium-salicylate was used, the diuresis from the injected kidney was always a little greater than that from the opposite side, and in one experiment, Dog 32, Figure 9, the injected kidney showed a moderate diuresis, while the opposite kidney failed to respond; the urine from the injected side was pale in color and of a much lower specific gravity. With theophylline-ethylene-diamine, the output from the injected kidney was usually slightly less than that from the opposite kidney. Urea and digi$\tan$ are less effective than the other diuretics included in this group. With digitan, particularly in larger doses, the diuresis from the injected 
side was somewhat less in degree. This may be due to the peripheral vasoconstrictor effect of the digitalis series on the renal vessels. It seems logical to conclude from the study of this group, that the mechanism of diuresis differs from that induced by the mercurial compounds (novasurol and salyrgan) and by one of the xanthine group (theocine-sodium-acetate), and that possibly an extra-renal site of action may be an important factor in the response to these drugs. Further investigation will be needed to explain satisfactorily the definite mechanism of diuresis from these two apparently differently acting groups of diuretics.

\section{CONCLUSIONS}

From observations on acute experiments with the anesthetized dog, rendered hydremic by the intravenous injection of saline solution, we draw the following conclusions in regard to the action of certain diuretics when introduced directly into the renal artery to one kidney (the left kidney).

1. Novasurol, salyrgan and theocine-sodium-acetate when injected in small doses, directly into the left renal artery of the dog, produce a diuresis from the left kidney and little change in the excretory activity of the right kidney; in somewhat larger doses diuresis from each kidney varies but little, while when still larger doses are used there follows an active diuresis from the right and a not increased or a decreased excretion from the left kidney (the kidney into whose artery the diuretic is directly injected).

2. Caffeine citrate, theobromine-sodium-salicylate, theophylline-ethylene-diamine, theophylline-calcium-salicylate, urea and digitan in contrast, produce approximately the same urinary excretion from each kidney, although the diuretic has been injected directly into the renal artery of only one kidney.

\section{BIBLIOGRAPHY}

1. Schroeder, W., Arch. f. exper. Path. u. Pharmakol., 1888, xxiv, 85. Über die diuretische Wirkung des Caffeins und der zu derselben Gruppe gehörenden Substanzen.

2. Barcroft, J. and Straub, H., J. Physiol., 1910-11, xli, 145. The secretion of urine.

3. Hayman, J. M., Jr., and Schmidt, C. F., Am. J. Physiol., 1927-28, lxxxiii, 502. The gaseous metabolism of the dog's kidney.

4. Richards, A. N. and Plant, O. H., J. Pharmacol. and Exper. Therap., 1915, vii, 485. Urine formation by the perfused kidney: Preliminary experiments on the action of caffeine.

5. Cushny, A. R. and Lambie, C. G., J. Physiol., 1921, 1v, 276. The action of diuretics.

6. Loewi, O., Fletcher, W. M. and Henderson, V. E., Arch. f. exper. Path. u. Pharmakol., 1905, liii, 15. Untersuchungen zur Physiologie und Pharmakologie der Nierenfunction. III. Über den Mechanismus der Caffein-diurese.

7. Phillips, C. D. F. and Bradford, J. R., J. Physiol., 1887, viii, 117. On the action of certain drugs on the circulation and secretion of the kidney. 
8. Gottlieb, R. and Magnus, R., Arch. f. exp. Path. u. Pharmakol., 1901, xlv, 223. Ueber Diurese. IV. Ueber die Beziehungen der Nierencirculation zur Diurese.

9. Starling, E. H., J. Physiol., 1899, xxiv, 317. The glomerular functions of the kidney.

10. Hayman, J. M., Jr. and Starr, I., J. Exper. Med., 1925, xlii, 641. Experiments on the glomerular distribution of blood in the mammalian kidney.

11. Richards, A. N. and Schmidt, C. F., Am. J. Physiol., 1924, 1xxi, 178. A description of the glomerular circulation in the frog's kidney and observations concerning the action of adrenalin and various other substances upon it.

12. Spiro, K. and Vogt, H., Ergebn. d. Physiol., 1902, i, 414. Physiologie der Harnabsonderung.

13. Spiro, P., Arch. f. exp. Path. u. Pharmakol., 1919, lxxxiv, 123. Über die Wirkung der Diuretika der Purinreihe auf den Stoffaustausch zwischen Blut und Geweben.

14. Ellinger, A., Heymann, P. and Klein, G., Arch. f. exp. Path. u. Pharmakol., 1921, xci, 1. Die treibenden Kräfte für den Flüssigkeitsstrom im Organismus. II. Quellungsdruck bei Eiweisskörper und Diurese.

15. Govaerts, P., Arch. internat. de pharmacodyn, et de thérapie, 1929, xxxvi, 99. L'Action Diuretique du Novasurol est-elle d'origine Rénale ou Tissulaire.

16. Schmidt, R., Arch. f. exper. Path. u. Pharmakol., 1922, xcv, 267. Über Diureseversuche an überlebenden Froschnieren.

17. Gremels, H., Arch. f. exp. Path. u. Pharmakol., 1928, 1xi, 130. Über die Wirkung einiger Diuretika am Starlingschen Herz-Lungen-Nierenpräparat.

18. Melville, K. I. and Stehle, R. L., J. Pharmacol. and Exper. Therap., 1928, xxxiv, 209, Mercury diuresis.

19. Nonnenbruch, W., München. med. Wchnschr., 1921, lxviii, 1282. Üeber die Wirkung des Novasurols auf Blut und Diurese.

20. Tezner, O., Med. Klin., 1923, xix, 788. Zum Mechanismus der Novasurolwirkung.

21. Saxl, P. and Heilig, Rl., Ztschr. f. d. ges. exper. Med., 1923, xxxviii, 94. Üeber die Novasurocdiurese.

22. Bohn, H., Klin. Wchns hr., 1923, ii, 352. Experimentelle Studien über die diuretische Wirkung des Novasurols.

23. Reinike, E., Ztschr. f. klin. Med., 1914, lxxix, 296. Nierenhypertrophie nach Digitalis.

24. Kasztan, M., Arch. f. exper. Path. u. Pharmakol., 1910, 1xiii, 405. Beiträge zur Kenntnis der Gefässwirkung des Strophanthins.

25. Fahrenkamp, C., Arch. f. exper. Path. u. Pharmakol., 1911, lxv, 367. Üeber die verschiedene Beeinflussung der Gefässgebiete durch Digitoxin.

26. Wallace, G. B. and Pellini, E. J., J. Phar macol. and Exper. Therap., 1926, xxvi, 397. The anti-diuretic effects of the caffein group in the dog.

27. Loeb, A., Arch. f. exper. Path. u. Pharmakol., 1906, liv, 314. Beiträge zur Physiologie der Niere.

28. Bogert, L. J., Underhill, F. P. and Mendel, L. B., Am. J. Physiol., 1916, xli, 189. Studies of the permeability of cellular membranes. I. The regulation of the blood volume after injections of saline solutions.

29. Fee, A. R., J. Physiol., 1929, 1xviii, 39. Studies on water diuresis. I. The effect of decerebration, anaesthesia and morphia upon water diuresis.

30. Ogden, E., Proc. Soc. Exper. Biol. and Med., 1930, xxvii, 506. Inhibition of water diuresis by amytal. 